\title{
Surge of COVID-19 Cases after Easing of Lockdown in Pakistan: A District Perspective
}

\section{Khan $\mathrm{H}^{*}$}

Department of Pathology, Nowshera Medical College, Pakistan

*Corresponding author: Dr. Hamzullah Khan, Associate Professor, Department of Pathology, Nowshera Medical College, Nowshera, Pakistan, Email: hamzakmc@gmail.com
Letter to Editor

Volume 4 Special Issue 1

Received Date: June 30, 2020

Published Date: July 08, 2020

DOI: $10.23880 /$ jidtm-16000S1-004

\section{Dear Editor,}

All over the world, the residents of all COVID-19 infected countries have experienced lockdown to contain the virus and to prevent it's human to human transmission. In Pakistan from the start there was a confusion to announce it or not due to the socio-economic effects of lockdown but in month of April all sectors agreed to officially announce lockdown. China took unprecedented measures were taken well in time to control the rapid spread of COVID-19 epidemics. They succeeded to adhere people to homes that were properly achieved by their improved Knowledge, attitude and practices towards COVID-19 [1]. They improved the detection rate and contained virus in mainland Wuhan, Hubei Province, by enhancing the quarantine and isolation strategy and putting stress on social distancing [2].

Strict measures to contain virus, like closure of schools, offices, roads and other transits, cancellation of all mass gatherings in order to give mandatory quarantine to uninfected people without knowing their viral status worked where implemented in true letter and spirit. In May 2020, the government relaxed the lock down and experienced a potential unexpected surge of COVID-19 cases in the country. According to the WHO report about $80 \%$ rise in cases was recorded after lifting the lockdown in the country [3]. By lifting the lockdown the government might have opened the windows for virus spread. We analyzed our COVID-19 data of District Nowshera and observed a dramatic surge in rise of positive cases as well as the number of tests performed. We observed that $5(1.13 \%)$ cases of the total burden reported till date, have been recorded in March 2020, followed by 57(12.84\%) in April, and huge rise of cases 263(59.23\%) were reported in May 2020 after lifting the lockdown. Only in 8 days of June 2020, the $119(26.26 \%$ ) cases are uploaded to district line list (Table $1 \&$ Figure 1).

Five times more number of positive cases was recorded in May 2020, as compared to the month of April. Similarly the total number of tests also increased the same way. The more annoying of all is the positivity ratio, if we take it for month of May 2020 out of total testes cases 265/844 (31.16\%) were positive.

\begin{tabular}{|c|c|c|c|c|c|}
\hline & \multicolumn{3}{|c|}{ Month } & Total \\
\hline Result & March & April & May & June 9 $^{\text {th }} \mathbf{2 0 2 0}$ & \\
\hline Negative & 23 & 159 & 566 & 160 & 908 \\
\hline Positive & 5 & 57 & 263 & 119 & 444 \\
\hline Percentage rise in positive cases & 1.13 & 12.84 & 59.23 & 26.8 & 444 \\
\hline Awaiting & 0 & 0 & 12 & 162 & 174 \\
\hline Inconclusive & 0 & 0 & 3 & 7 & 10 \\
\hline Total & 28 & 216 & 844 & 448 & 1536 \\
\hline Percentage rise in number of tests & 1.82 & 14.06 & 54.95 & 29.17 & 1536 \\
\hline
\end{tabular}

Table 1: Month wise Tests and Positive Cases Data. 


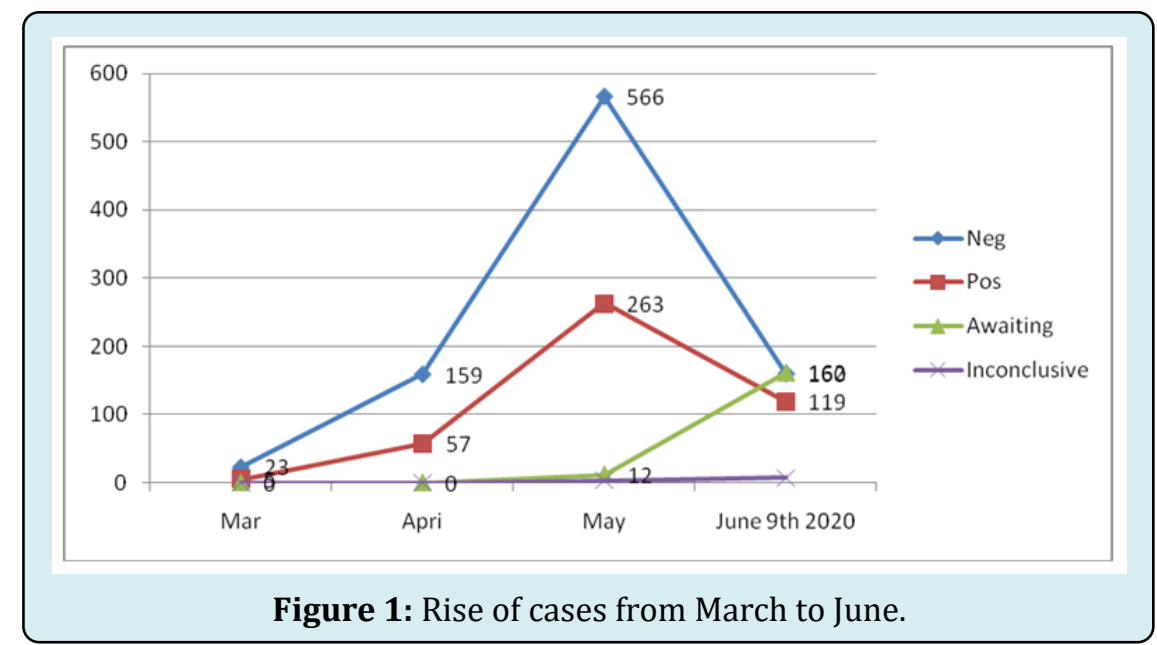

One can argue that one week of Eidul-Fitr vacations and lifting the lockdown would have worsen the situation and would have contributed to this rise number of cases. Besides this there is a stigma associated with the disease and people have fear of coming to hospitals and the actual burden may be much more than what we see from the available data which shows only the tip of the iceberg.

Furthermore how the government plans to combat COVID-19 is still not clear. There is no clear policy from the government side as the strategies to contain virus in early stages of pandemic resulted in poor outcome. There are discussions in social media and government news letters that they are planning for imposition of another lockdown which sets to fail for several reasons including the scuffle between the center and the provinces continues to pose a challenge. In order to contain virus transmission, several measures like border control, airport screening, quarantine, travel restrictions need to be implemented in true spirit. Studies from china have reported that travel restrictions have reduced the exportation of virus by 81 to $90 \%[1,4]$.

In a letter sent to the provincial government of Punjab on Sunday ( $7^{\text {th }}$ May 2020) [5], WHO representative for Pakistan, Mr. Palitha Mahipala said the country did not meet any of the organization's six technical criteria for easing a lockdown. They reported $24 \%$ increase in positive cases after easing the lockdown, that is still lower than what we observed in May 2020 (more than 36\%) increase in positive cases was recorded). We concluded that the situation in Pakistan is much worse and panic what we observe from the data. There is need for social distancing, complete lockdown for 14 days at least and reducing the stigma to rebuild the trust of the community in government hospitals to attend it for free testing for viral detection.

\section{References}

1. Zhong BL, Luo W, Li HM, Zhang QQ, Liu XG, et al. (2020) Knowledge, attitudes, and practices towards COVID-19 among Chinese residents during the rapid rise period of the COVID-19 outbreak: a quick online cross-sectional survey. Int J Biol Sci 16(10): 1745-1752.

2. Tang B, Xia F, Tang S, Liang J, Xiao Y, et al. (2020) The effectiveness of quarantine and isolation determine the trend of the COVID-19 epidemics in the final phase of the current outbreak in China. Int J Infect Dis 95: 288-293.

3. Jamal U (2020) Pakistan Plans Another COVID-19 Lockdown. Will It Work? The Diplomat.

4. Chinazzi M, Davis JT, Ajelli M, Gioannini C, Litvinova M, et al. (2020) The effect of travel restrictions on the spread of the 2019 novel coronavirus (COVID-19) outbreak. Science 368(6489): 395-400.

5. World Health Representative for Pakistan (2020) WHO office Islamabad. Intermittent lockdown across the country for mitigating COVID-19 outbreak in Pakistan, $7^{\text {th }}$ June 2020, in reply to: PAK.WR.06.08, Reference AF.1.33/20. 